ISSN 1112-9867

Available online at $\quad$ http://www.jfas.info

\title{
ENERGY-EFFICIENT ADJUSTABLE SPEED DOUBLE INVERTER-FED WOUND- ROTOR INDUCTION MOTOR DRIVE
}

\author{
G. Tutaev ${ }^{*}$, M. Bobrov, Y. Fedotov \\ Ogarev Mordovia State University, Dept. of Elect. \& Electrical Engineering, Saransk, 43005, \\ Russia
}

Published online: 08 August 2017

\begin{abstract}
The mathematical and analytical models of adjustable speed electric drive based on double inverter-fed induction motor are considered and analyzed in the article, the main equations which describe energy performances of such type of AC electric drive system are determined. The influence of excitation frequency on energy performances of double inverter-fed induction motor in steady-state at orthogonal flux vector control is considered in the article. The condition ensures minimum of stator steel losses at a predetermined rotor speed and can operate at speeds up to double rated without the magnetic flux reducing is presented. This possibility is one of the most important advantages of this type of electric drive over others types of AC drives for many technological processes.
\end{abstract}

Key words: power, double-fed wound-rotor induction motor drive, steel and total losses, efficiency, energy-efficient control algorithm.

\section{INTRODUCTION}

Recently there is a stable tendency in modern industry to switching to the new energyefficient technologies. Using of adjustable speed AC electric drive concerns to them. In scientific literature there are a great number of publications describing optimization operation modes of induction and synchronous AC drives, and also drives based on double-fed woundrotor induction motor by energy criterion.

Author Correspondence, e-mail: author@gmail.com

doi: http://dx.doi.org/10.4314/jfas.v9i2s.90 
Double inverter-fed induction motor supplied by two power converters at rotor and stator circuits is one of the options of electric drive based on double-fed machine.

More than half of all electricity produced in the world is consumed by variable speed electric drives. It's obviously that research goals connected with the design of energy-efficient electric drive systems because it is very important nowadays. Variable speed AC drives is the most reliable and cost-effective way of electrical energy into mechanical energy conversion. In technological processes with heavy operation modes are used variable speed AC drives based on double-fed wound-rotor induction machines. Double inverter-fed induction motor is one of the options of electric drive based on double-fed machine.

\section{Theory and mathematical model}

Electric drive based on double inverter-fed induction motor is composed of a basic induction motor with wound rotor supplied by two power converters which allows controlling of four variables and gives the possibility to control of energy mode of the machine. The concept and some proposed motor energy-efficient control options for electric drive based on double inverter-fed induction motor are presented in detail in [1][2][3][4].

Equations of mathematical models describing the electromagnetic processes in double inverter-fed induction motor presented in [8]. Determination of the eddy current losses and hysteresis losses coefficient for the particular type of machine is carried out by losses values (calculated or experimentally determined by well- known methods) at two points in the operating frequency range of machine idling operation [6]. For the motor 4AK250SB4UZ with rated power $55 \mathrm{~kW}$ values of losses coefficient are: $R_{e c}=656.5 \mathrm{Ohm}, K_{c}=1.4 \mathrm{H}$.

Electric drive based on double inverter-fed induction motor structural scheme and vector diagram are presented at Fig. 1 

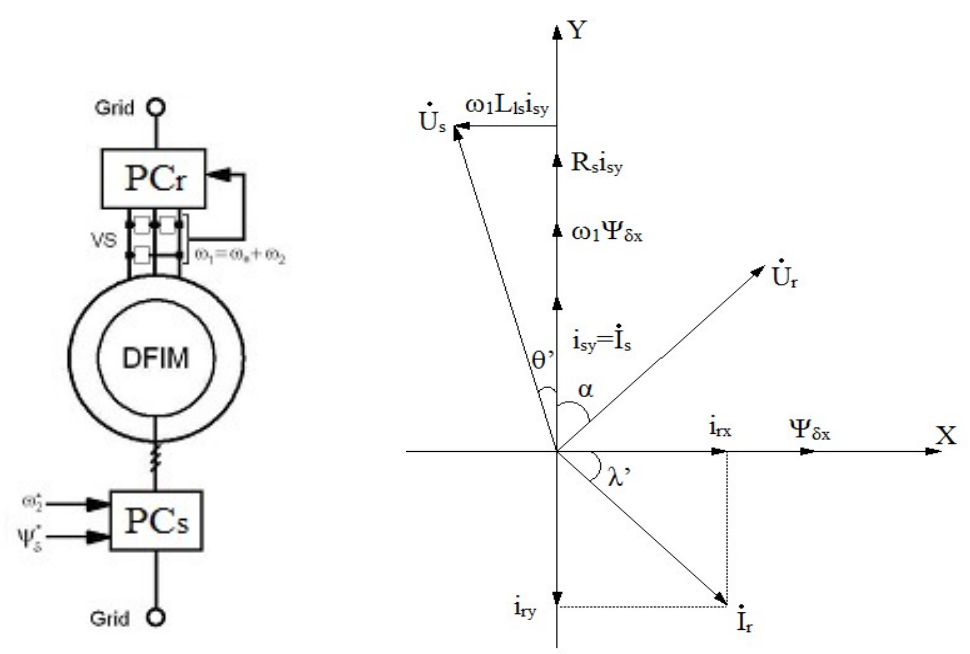

Fig.1. Electric drive based on double inverter-fed induction motor structural scheme and vector diagram

For double inverter-fed induction motor in steady-state the electrical balance equation of the armature and excitation windings considering [5][7][9-13] can be written:

$$
\left\{\begin{array}{l}
u_{s x}=-\omega_{1} L_{l s}\left(-i_{r y}+\omega_{1} \frac{\Psi_{\delta x}}{R_{e c}}+\frac{\Psi_{\delta x}}{K_{h}}\right), \\
u_{s y}=R_{s}\left(-i_{r y}+\omega_{1} \frac{\Psi_{\delta x}}{R_{e c}}+\frac{\Psi_{\delta x}}{K_{h}}\right)+\omega_{1} \Psi_{\delta x}, \\
u_{r x}=\frac{R_{r}}{L_{m}} \Psi_{\delta x}-\omega_{2} L_{l r} i_{r y}, \\
u_{r y}=R_{r} i_{r y}+\omega_{2} \frac{L_{r}}{L_{m}} \Psi_{\delta x} .
\end{array}\right.
$$

Current components at axis can be written:

$$
\left\{\begin{array}{l}
i_{r x}=\frac{\Psi_{\delta x}}{L_{m}}=\text { const }, \\
i_{s y}=-i_{r y}+\omega_{1} \frac{\Psi_{\delta x}}{R_{e c}}+\frac{\Psi_{\delta x}}{K_{h}}
\end{array}\right.
$$

From the vector diagram should:

$$
\left\{\begin{array}{l}
u_{s x}=U_{s} \sin \left(-\theta^{\prime}\right), \\
u_{s y}=U_{s} \cos \left(-\theta^{\prime}\right), \\
u_{r x}=U_{r} \sin \alpha, \\
u_{r y}=U_{r} \cos \alpha .
\end{array}\right.
$$


Where: $\theta^{\prime}$ - phase offset angle between current and armature voltage vectors, $\alpha$ rotor voltage vector phase, determined by excitation frequency, $\theta^{\prime}+\alpha=\delta$ - phase offset angle between armature voltage $\dot{U}_{s}$ and excitation voltage $\dot{U}_{r}$ vectors.

Looking at equation (1) and (3) the electrical balance equation of the armature and excitation windings can be written:

$$
\left\{\begin{array}{l}
U_{s} \sin \left(-\theta^{\prime}\right)=-\omega_{1} L_{l s} i_{s y}, \\
U_{s} \cos \left(-\theta^{\prime}\right)=R_{s} i_{s y}+\omega_{1} \Psi_{\delta x}, \\
U_{r} \sin \alpha=\frac{R_{r}}{L_{m}} \Psi_{\delta x}-\omega_{2} L_{l r} i_{r y}, \\
U_{r} \cos \alpha=R_{r} i_{r y}+\omega_{2} \frac{L_{r}}{L_{m}} \Psi_{\delta x} .
\end{array}\right.
$$

For steady-state of double inverter-fed induction motor from (6) excitation voltage vector magnitude:

$$
\begin{aligned}
& U_{r}=\frac{R_{r} \Psi_{\delta x}-\omega_{2} L_{m} L_{l r} i_{r y}}{L_{m} \sin \alpha}, \\
& U_{r}=\frac{R_{r} L_{m} i_{r y}+\omega_{2} L_{r} \Psi_{\delta x}}{L_{m} \cos \alpha} .
\end{aligned}
$$

Then active current component:

$$
i_{r y}=i_{r x}\left[\frac{R_{r} \cos \alpha-\omega_{2} L_{r} \sin \alpha}{R_{r} \sin \alpha+\omega_{2} L_{l r} \cos \alpha}\right] .
$$

From the vector diagram seen:

$$
\begin{gathered}
i_{r x}=\frac{\Psi_{\delta x}}{L_{m}}=I_{r} \sin \lambda, \\
i_{r y}=-I_{r} \cos \lambda .
\end{gathered}
$$

The angle of excitation current vector:

$$
-\operatorname{tg} \lambda=\frac{R_{r} \sin \alpha+\omega_{2} L_{l r} \cos \alpha}{R_{r} \cos \alpha-\omega_{2} L_{r} \sin \alpha}
$$

Equation (9) transformed in: 


$$
i_{r y}=-\frac{i_{r x}}{\operatorname{tg} \lambda}=-\frac{\Psi_{\delta x}}{L_{m} \operatorname{tg} \lambda} .
$$

The angle of excitation voltage vector determined by equation system (6):

$$
\operatorname{tg} \alpha=\frac{R_{r} \Psi_{\delta x}-\omega_{2} L_{m} L_{l r} i_{r y}}{R_{r} L_{m} i_{r y}+\omega_{2} L_{r} \Psi_{\delta x}}=\frac{R_{r} \operatorname{tg} \lambda-\omega_{2} L_{l r}}{R_{r}+\omega_{2} L_{r} \operatorname{tg} \lambda} .
$$

If $R_{s} \approx 0$ for high-power electric machines, that armature voltage can be written:

$$
\begin{aligned}
& U_{s}=-\frac{\omega_{1} L_{l s}}{\sin \left(-\theta^{\prime}\right)}\left[\frac{\Psi_{\delta x}}{L_{m} \operatorname{tg} \lambda}+\omega_{1} \frac{\Psi_{\delta x}}{R_{e c}}+\frac{\Psi_{\delta x}}{K_{h}}\right], \\
& U_{s}=\omega_{1} \frac{\Psi_{\delta x}}{\cos \left(-\theta^{\prime}\right)} .
\end{aligned}
$$

Load angle of double inverter-fed induction motor or angle of armature voltage:

$$
-\operatorname{tg} \theta^{\prime}=-L_{l s}\left(\frac{1}{L_{m} \operatorname{tg} \lambda}+\frac{\omega_{1}}{R_{e c}}+\frac{1}{K_{h}}\right) .
$$

The dependence between load angle and armature voltage vector is:

$$
\operatorname{tg} \lambda=\frac{L_{l s} R_{e c} K_{h}}{L_{m}\left(R_{e c} K_{h} \operatorname{tg} \theta^{\prime}-\omega_{l} L_{l s} K_{h}-L_{l s} R_{e c}\right)} .
$$

Current excitation $\dot{I}_{r}$ phase vector relative voltage excitation vector $\dot{U}_{r}$ dependent at excitation frequency $\omega_{2}$, which determines the angle $\alpha$ of the load on the shaft of the double inverter-fed induction motor, that determines the angle $\theta^{\prime}$ and, accordingly, angle $\lambda$ :

$$
\phi_{r}=\pi-(\alpha+\lambda) \text {. }
$$

The electromagnetic torque equation for double inverter-fed induction motor at orthogonal control looks:

$$
M_{e}=-\frac{3}{2} p_{n}\left(\Psi_{\delta x} i_{r y}-\Psi_{\delta y} i_{r x}\right)=-\frac{3}{2} p_{\Pi} \Psi_{\delta x} i_{r y}
$$

After substitution of rotor current from (11):

$$
M_{e}=3 \frac{\Psi_{\delta x}^{2}}{L_{m} \operatorname{tg} \lambda} .
$$

The electrical balance equation for double inverter-fed induction motor for steadystate can be written:

$$
P_{s} \pm P_{r}=P_{2}+P_{\text {scop }}+P_{s s t}+P_{r c o p}+P_{r s t}+P_{\text {мec }}+P_{a},
$$


where $P_{s}$ and $P_{r}$ - active and reactive power consumed by the windings of the armature and excitation, $P_{2}$ - mechanical power on the motor shaft, $P_{\text {scop }}$ and $P_{\text {rcop }}-$ stator and rotor copper losses, $P_{s s t}$ and $P_{r s t}$ - stator and rotor steel losses, $P_{\text {мес }}$ and $P_{a}-$ mechanical and added losses.

Rotor steel losses aren't considered because the value of excitation frequency is small, and stator copper losses can be written:

$$
P_{\text {scop }}=\frac{3}{2}\left(\frac{\Psi_{\delta x}}{L_{m} \operatorname{tg} \lambda}+\omega_{1} \frac{\Psi_{\delta x}}{R_{e c}}+\frac{\Psi_{\delta x}}{K_{h}}\right)^{2} R_{s}=\frac{3}{2} i_{s y}^{2} R_{s} .
$$

Active and reactive power consumed by the windings of the armature, defined by the relations:

$$
\begin{aligned}
& P_{s}=\frac{3}{2} I_{s} U_{s} \cos \theta^{\prime}=\frac{3}{2}\left(i_{s x} u_{s x}+i_{s y} u_{s y}\right), \\
& Q_{s}=\frac{3}{2} I_{s} U_{s} \sin \theta^{\prime}=\frac{3}{2}\left(i_{s x} u_{s y}-i_{s y} u_{s x}\right) .
\end{aligned}
$$

Active and reactive power consumed by the windings of the rotor defined by the relations:

$$
\begin{aligned}
& P_{r}=\frac{3}{2}\left(i_{r x} u_{r x}+i_{r y} u_{r y}\right)=\frac{\omega_{2}}{2} M_{e}\left[\frac{R_{r} \operatorname{tg} \lambda}{\omega_{2} L_{m}}+\frac{R_{r}}{\omega_{2} L_{m} \operatorname{tg} \lambda}-1\right], \\
& Q_{r}=\frac{3}{2}\left(i_{r x} u_{r y}-i_{r y} u_{r x}\right)=\frac{\omega_{2}}{2} M_{e}\left[\frac{L_{r} \operatorname{tg} \lambda}{L_{m}}+\frac{L_{l r}}{\left.L_{m} \operatorname{tg} \lambda\right]}\right.
\end{aligned}
$$

After describing the mathematical model of double inverter-fed induction motor it would be appropriate to describe and analysis the analytical models of this machine.

\section{Simulation and analytical model analysis}

Characteristic curve of double inverter-fed induction motor losses from the excitation frequency at the rated load is shown at fig. 2. The condition (15) ensures minimum of stator steel losses at a predetermined rotor speed and can operate at speeds up to double rated without the magnetic flux reducing $[14,15]$.

$$
\omega_{1}=-\omega_{2}=\frac{\omega_{e}}{2}
$$




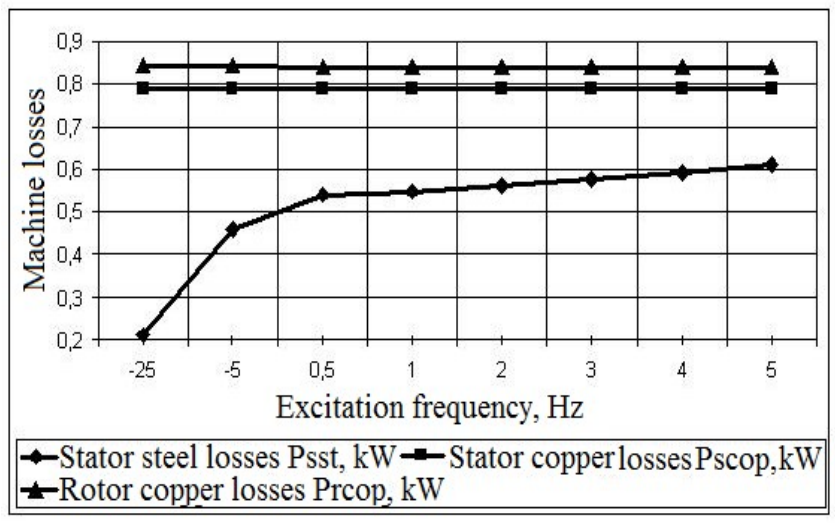

Fig.2. Double inverter-fed induction motor losses from the excitation frequency at the rated load characteristic curve

In a closed-loop control system or rotor speed when changing the excitation frequency and the load on the shaft close to rated, there is a redistribution of the active power in the armature and excitation circuits and the efficiency remains practically constant (Figure 3).

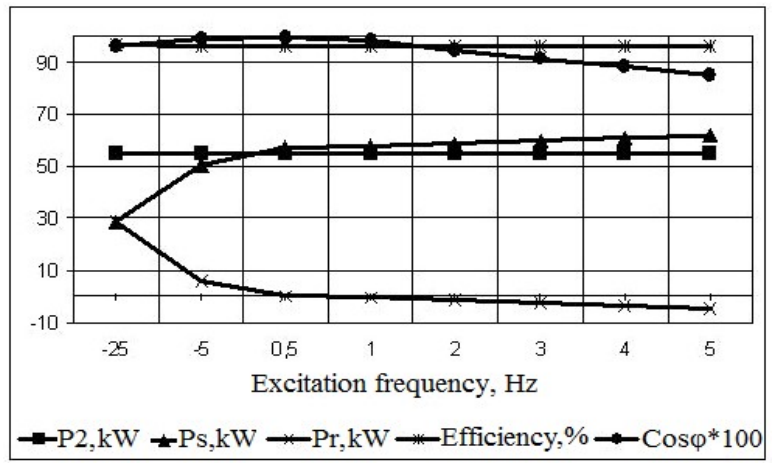

Fig.3. Energy performance at different values of excitation frequency

Increasing the excitation frequency connect with a small reduction of efficiency due to the stator steel losses increasing. This is particularly noticeable at low loads when these losses can be compared with rotor copper losses (Fig. 4). As the load increases significantly increase the copper losses and for a predetermined excitation frequency the constant stator steel losses isn't considered.

Power factor $\cos \varphi \Sigma$ decreases with increasing excitation frequency because reactive power in excitation circuit increasing. High values of $\cos \varphi \Sigma$ are achievable without stator active power recuperation into the grid, i.e. with active power consumption by the excitation winding. 


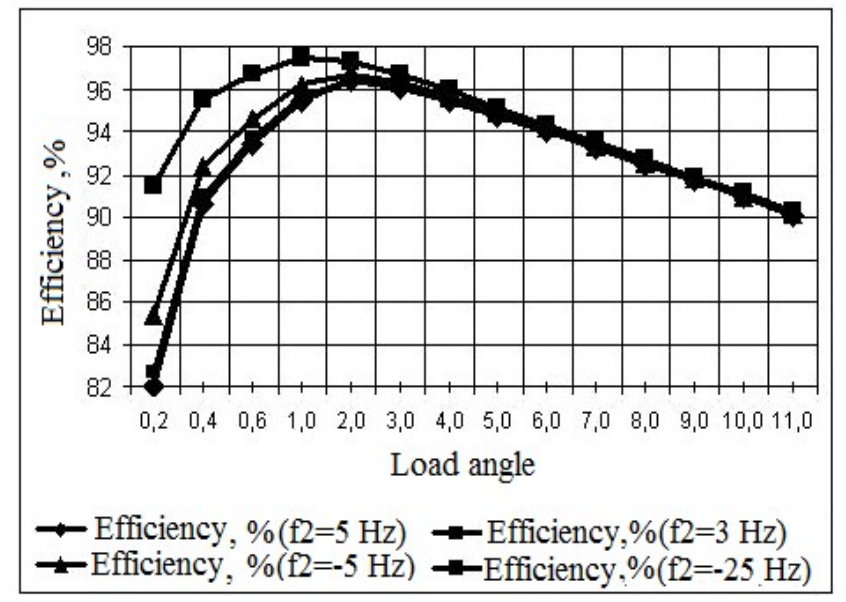

Fig.4. Efficiency at different values of excitation frequency

Then from (14) is determined by the minimum value of the excitation frequency at which the entire load range there will be no energy recuperation.

$$
\omega_{2 o p t}<\frac{R_{r}\left(\operatorname{tg}^{2} \lambda+1\right)}{L_{m} \operatorname{tg} \lambda} .
$$

Using the counter rotation of the rotor and the motor magnetic field can increase $\cos \varphi \Sigma$ (Fig. $5)$.

However, this increases the active power consumption by the excitation circuit and using condition (17) is possible to use two identical power converters, with rated power are equal to half of the base machine power (Fig. 3). But in this case, high efficiency obtains a very low power factor $\cos \varphi \Sigma$ at low loads. The excitation frequency is a multicriterion parameter. In addition to the sliding power it determines the power heating elements.

Rotor power:

$$
S_{r}=\sqrt{P_{r}^{2}+Q_{r}^{2}} .
$$

$\cos \varphi_{\Sigma}$ and efficiency calculated:

$$
\cos \phi_{\Sigma}=\frac{P_{s} \pm P_{r}}{S_{s}+S_{r}}, \quad \eta_{\Sigma}=\frac{P_{2}}{P_{s} \pm P_{r}} .
$$




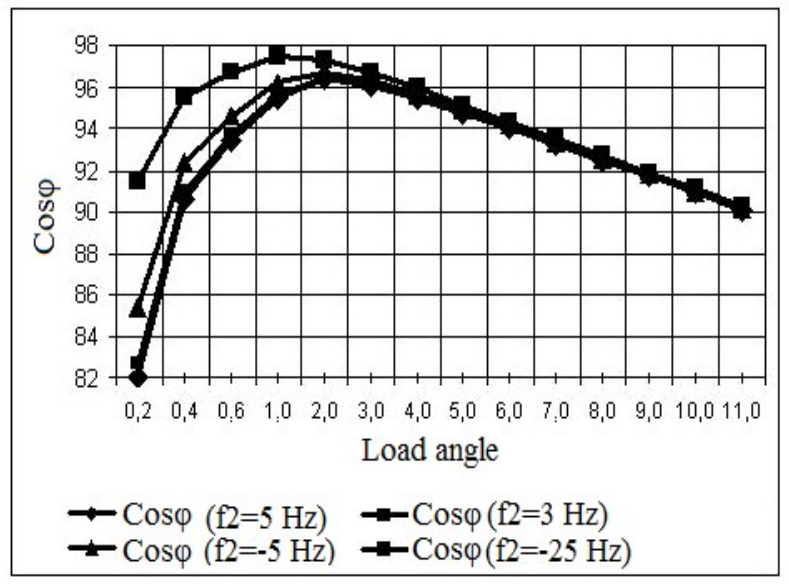

Fig.5. $\operatorname{Cos} \varphi \Sigma$ at different values of excitation frequency

\section{Experimental results}

Before the experiment the energy values of the $4 \mathrm{AK} 160 \mathrm{M} 4 \mathrm{YZ}$ induction motor $\left(\mathrm{P}_{2 \text { rat }}=11\right.$ $k W$ ) were calculated taking into account motor windings losses and stator steel losses for two values of the excitation frequency $\left(f_{2}=5 \mathrm{~Hz}\right.$ and $\left.\mathrm{f}_{2}=-5 \mathrm{~Hz}\right)$ at the rated values of magnetic flux and rotor speed. The rotor steel losses were not taken into account because of their smallness at a low excitation frequency values. In the course of the experiment the stator and rotor voltages and currents, the shaft rotation frequency, and the active power consumed were measured. The value of the magnetic flux was estimated by the observer.

At the figure (6) analytically determined and experimentally obtained energy characteristics of double inverter-fed induction motor for two values of excitation frequency are presented. The rated values of the $4 \mathrm{AK} 160 \mathrm{M} 4 \mathrm{YZ}$ motor parameters are $\eta_{\mathrm{r} \Sigma}=0.865$ and $\cos \varphi_{n \Sigma}=0.86$.

In the calculated rated operation mode at the implementation of the orthogonal control, the efficiency of the motor and the total power factor $\cos \varphi_{\mathrm{r} \Sigma}$ of the stator and rotor circuits at the excitation frequency $\mathrm{f}_{2}=5 \mathrm{~Hz}$ significantly exceed the nominal values of the base motor. The experimentally obtained value of the total efficiency is $\eta_{\Sigma}=0.88$ below the calculated efficiency by $2.9 \%$. The experimental power factor of $\cos \varphi_{\Sigma}=0.89$ is equal to the calculated value.

The transition to the magnetic field and the rotor counter rotation $\left(f_{2}=-5 \mathrm{~Hz}\right)$ leads to an increase in both calculated and experimental energy parameters, which is explained by a decrease stator steel losses. 
The difference in the theoretical and experimental values of the efficiency can be explained by the effect of additional losses on the phase current and voltages harmonic components due to their non-sinusoidal at supplying the motor windings from frequency power converters. In addition, mechanical, additional losses and brush losses which are most pronounced at low loads, when the mechanical power is low are also affected. As the load increases, these losses change insignificantly compared to the increasing mechanical power and the total losses, which determined the efficiency of the motor drive.

The power factor turned out to be close to the calculated values for both excitation frequencies values, since in the experiment their calculated values influencing $\cos \varphi$ were maintained. 

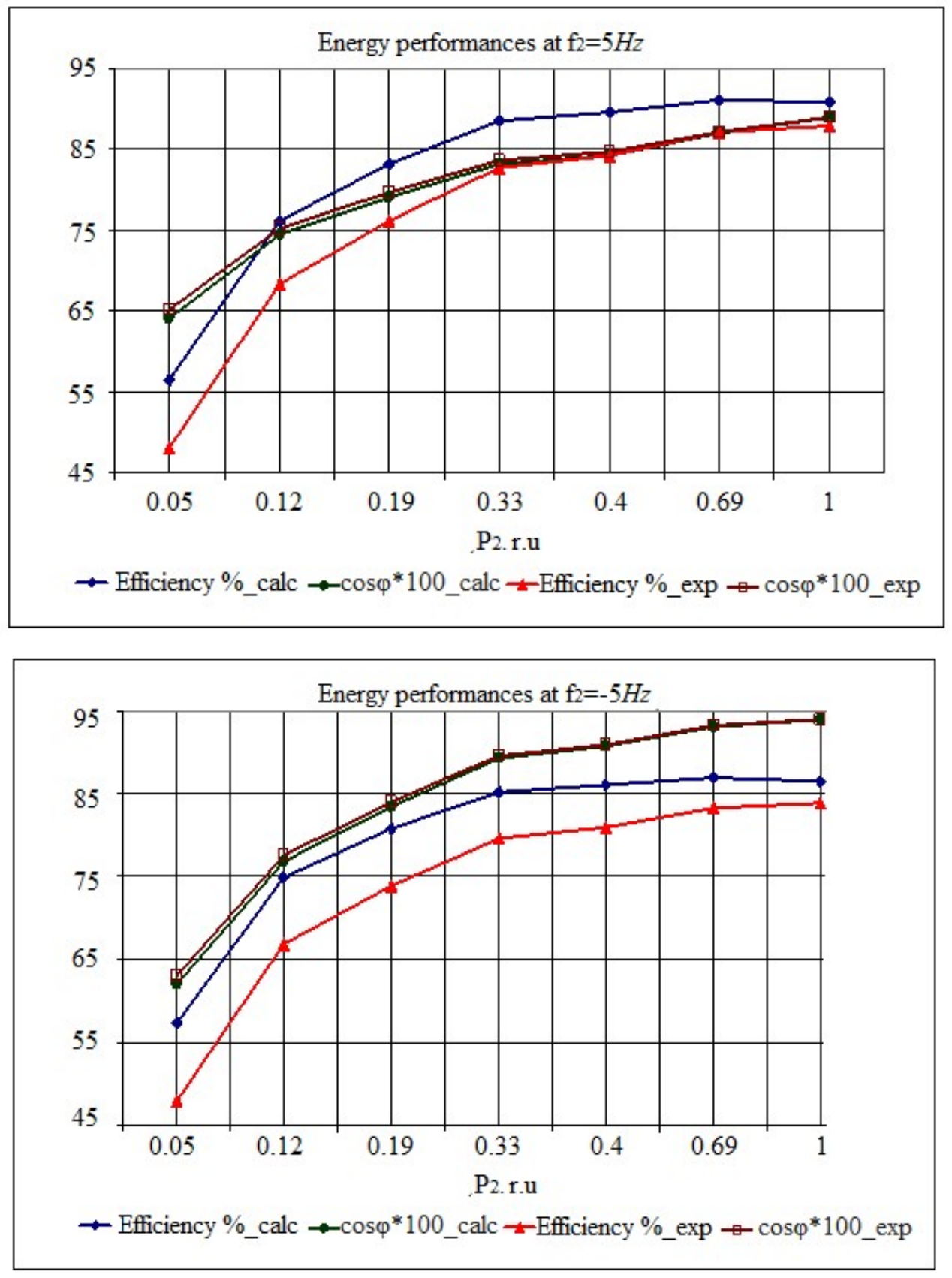

Fig.6. Experimental results of energy performances of electric drive based on double inverter-fed induction motor

\section{CONCLUSION}

Control of excitation frequency value has a prevail influence on energy performances of double inverter-fed induction motor, in particular stator steel losses which can be reduced with reducing of excitation frequency. Reducing the excitation frequency and switching to a counter rotor rotation and the machine magnetic field can significantly increase the power 
factor $\cos \varphi \sum$ value of double inverter-fed induction motor, but it makes necessary to increase the rated power of power converter in rotor circuit. Optimal value of the excitation frequency by energy performance depends on the machine parameters and is in the range of $1 \div 3 \mathrm{~Hz}$.

\section{ACKNOWLEDGMENTS}

The article was prepared as the part of applied research (AR) according to the Agreement on the provision of subsidy No. 14.574.21.0135 with the financial support of Russian Federation Ministry of Education and Science. The unique identifier of AR is RFMEFI57417X0135. »

\section{REFERENCES}

[1] Gennady Tutaev. Rotor speed estimation in control system of electric drive based on induction inverter-fed motor/Gennady Tutaev, Maxim Bobrov // Proceedings of the 2016 IX International Conference on Power Drives Systems (ICPDS), p. 1-4.

[2] G. M. Tutaev. Energy-efficient control options of electric drive based on asynchronous converter-fed motor/ G.M. Tutaev, A.V. Volkov, M.A. Bobrov // Proceedings of the 2016 13th International Scientific-Technical Conference on Actual Problems of Electronics Instrument Engineering (APEIE), p. 88-93.

[3] Sonin Yu.P., Gulyaev I.V. Induction inverter-fed motor. - Saransk: OMSU publishing, 1998. - p 68 .

[4] A.c. 1610589 USSR. A method for controlling of double-fed motor based on induction motor with wound rotor and a device for its implementation / Yu.P. Sonin, Yu.G. Shakaryan, Yu.I. Prusakov, S.A. Yushkov, I.V. Gulyaev (USSR). Published 30.11.1990， Bul. № 44-p 7.

[5] Tutaev G.M. Dynamic processes simulation in the generalized electromechanical system/ G.M. Tutaev, I.V. Gulyaev, A.N. Lomakin, I.S. Yushkov // Proceedings of the IX International Conference "Actual problems of electronic instrument (APEI-2008) ». In 7 tomes. - Novosibirsk: Novosibirsk State Technical University publishing house, 2008. - T. 7. - p. 129-133.

[6] Kopylov I. P. Design of electric machines/ I.P. Kopylov. - M.: Energy, 1980. - 495 p.

[7] Vinogradov A.B. Allowance of steel losses, saturation and skin effect in the simulation of dynamic processes in the frequency-controlled induction drive / A.B. Vinogradov // Russian Electrical Engineering. - 2005.- №5. - p. 57-61.

[8] Gulyaev I.V. Mathematical model of dynamic processes in the generalized electromechanical system allowance of steel losses and saturation/I.V. Gulyaev, G. M. Tutaev // Proceedings of the 2007 V International Conference on Power Drives Systems (ICPDS), p. 256-259. 
[9] Waide P.; Brunner C. Energy-efficiency policy opportunities for electric motor-drive system. OECD/IEA, 2011.

[10] Hrkel M., Vittek J., Biel Z. Maximum Torque per Ampere Control Strategy of Induction Motor with Iron Losses. 2012 ELEKTRO.

[11] Ben Ali A., Abdelati R., Mimouni Faouzi M., Dhifaoui R. Maximum-torque and maximum-efficiency rotor flux selection of an induction motor in transient regime // International Journal of sciences and Techniques of Automatic control \& computer engineering. IJ-STA. 2010. Volume 4, № 2 .

[12] Sidek, N.K.; Rosmin, N.; Rahman, H.A.; Hassan, M.Y.; Hussin, F.; Musta'amal, A.H., "Efficiency optimization of an induction machine using optimal flux control," Energy Conversion (CENCON), 2014 IEEE Conference on, pp.219,224, 13-14 Oct. 2014

[13] Ronggang Ni ; Dianguo Xu ; Gaolin Wang ; Li Ding ;; Lizhi Qu, Maximum Efficiency Per Ampere Control of Permanent-Magnet Synchronous Machines, Industrial Electronics, IEEE Transactions on, Volume: 62, Issue: 4, Publication Year: 2015, Page(s): 2135- 2143.

[14] G. M. Tutaev. Double inverter-fed induction motor energy performances research at analytical model/ G.M. Tutaev, M.A. Bobrov // 2017 International Siberian Conference on Control and Communications, SIBCON 2017 - Proceedings 7998483

[15] G.M. Tutaev, M.A. Bobrov, I.V. Gulyaev. Evaluation of the energy characteristics of an asynchronous inverter-fed induction motor at different approximations of the magnetization curve // Russian Electrical Engineering, Volume 88, Issue 6, 1 June 2017, Pages 321-325.

\section{How to cite this article:}

Tutaev G, Bobrov M, Fedoto Y. Energy-efficient adjustable speed double inverter-fed woundrotor induction motor drive. J. Fundam. Appl. Sci., 2017, 9(2S), 1158-1170. 